\title{
Geologia
}

\section{Métodos e técnicas aplicados na avaliação ambiental do aterro da BR-040 da Prefeitura Municipal de Belo Horizonte - MG}

\author{
Helio Antonio de Sousa \\ Geólogo, MSc.pela UFOP.E-mail:helio@cprmbh.gov.br \\ Hubert Mathias Peter Roeser \\ Dr., Professor do Depart. de Geologia da UFOP, Orientador \\ E-mail:hubert@degeo.ufop.br \\ Antônio Teixeira de Matos \\ Dr., Professor do Depart. de Engenharia Agrícola da UFV, Co-Orientador \\ E-mail:atmatos@ufv.br
}

\section{Resumo}

Esse trabalho representa a primeira parte da seqüência de três artigos a serem publicados pela Revista Escola de Minas REM, sobre a avaliação do nível de contaminação por metais pesados e substâncias orgânicas na área do Aterro Sanitário da Prefeitura Municipal de Belo Horizonte-MG, Brasil, como resultado da Dissertação de Mestrado na área de Concentração Geoquímica Ambiental, defendida junto ao Departamento de Geologia da UFOP, em julho de 1998. Essa primeira publicação trata-se dos métodos e técnicas utilizados na realização dos trabalhos. A discussão dos resultados será feita nos próximos dois artigos. A área está situada às margens da BR-040, km 2, na divisa do município de Belo Horizonte com o município de Contagem. Amostras de solos coletadas em áreas sem lixo sobreposto e em áreas cobertas por lixo urbano com diferentes idades, além de amostras de água superficial, do nível freático e de chorume, foram analisadas por meios físicos e químicos. As análises físicas incluíram análises textural, mineralógica e micromorfológica. As análises químicas permitiram determinar a capacidade de troca catiônica dos diversos solos da área. As formas de retenção dos metais no solo foram investigadas por extrações químicas seqüenciais nas seguintes frações: total, trocável, matéria orgânica e óxidos de ferro e manganês, realizadas em amostras de 07 perfis de solos e de 02 trincheiras abertas no perfil de resíduos sólidos. Para o estudo das águas, foram coletadas e analisadas 09 amostras, incluindo as de chorume. As análises físicas e químicas dos solos permitiram o entendimento da mobilidade dos metais pesados e sua dispersão nos perfis.

Palavras-chave: aterro sanitário, poluição por metais pesados e orgânicos, poluição de águas e solos.

\begin{abstract}
This work evaluated the level of heavy metals contamination of a sanitary landfill area in Belo Horizonte, Minas Gerais, Brazil. This landfill is situated at the edge of the BR-040 highway, and is close to the Belo Horizonte-Contagem borderline. Samples offree-of-waste soils and soils covered by urban waste of different ages were analyzed by physical and chemical means. The same analysis was performed on superficial and underground water samples, and leachate samples. The physical analyses included textural, mineralogical, and micromorphological analyses. Chemical analyses determined the cationic change capacity of the different soils. Several ways of metal retention in the soils were investigated by sequencial extraction procedures in the following fractions: (1) total fraction, (2) exchanged fraction, (3) bound to organic matter fraction, (4) bound to Fe oxides fraction, and (5) bound to Mn oxides fraction using samples from 07 soil profiles, and 02 trenches that were opened in the waste pile. Nine samples were taken, including leachate samples for water analysis. Physical and chemical analyses of the soils allowed the understanding of the mobility of the heavy metals, and their dispersion in the profiles. The sanitary landfill area is essentially composed of young soils of acid $\mathrm{pH}$, and clayey to clayey loamy sandy texture. The mineralogy of these soils is composed by minerals from acid rocks (gneiss) and basic rocks (gabbro and micro gabbro). Kaolinite is the main minerals of the clay fraction. These studies show that the superficial layers of soil retain part of the heavy metals that come from solid waste piles. In addition, superficial and underground waters in the sanitary landfill are contaminated by organic and inorganic compounds.

Keywords: sanitary landfill, heavy metals and organics substances contamination, water and soils contamination in sanitary landfill.
\end{abstract}

Artigo recebido em 20/08/2002 e aprovado em 07/11/2002. 


\section{Introdução}

A poluição do solo e de águas superficiais e subterrâneas, provocada por resíduos sólidos urbanos, passou a ser motivo de estudos em todo o mundo, principalmente nos países industrializados, dado ao reconhecido potencial poluidor e o grande volume gerado diariamente. A possibilidade de contaminação ambiental, associada à necessidade de grandes áreas para a disposição e tratamento, tornou a solução para o problema do lixo urbano um dos mais sérios desafios para as administrações públicas municipais.

Por esse motivo, o propósito dessa publicação é divulgar, em primeira mão, os resultados dos trabalhos relativos aos estudos geoquímicos realizados na área do Aterro Sanitário da BR-040, da Prefeitura Municipal de Belo Horizonte - MG, que foram apresentados como Dissertação de Mestrado na área de Concentração Geoquímica Ambiental, junto ao Departamento de Geologia - DEGEO, da Universidade Federal de Ouro Preto UFOP, em junho de 1998, cujo título é: "Estudos da contaminação ambiental na área do Aterro Sanitário da BR-040, da Prefeitura Municipal de Belo Horizonte -MG".

Vale ressaltar que o material aqui apresentado é apenas um documento resumido de um minucioso trabalho de investigação sobre a questão ambiental na área do aterro, com o objetivo de mostrar procedimentos adequados de pesquisa em área de disposição de lixo urbano, visando a identificar o grau de poluição ambiental de águas e solos provocada por metais pesados e substâncias orgânicas liberados por processos físico-químicos responsáveis pela degradação e lixiviação do material disposto.

O trabalho enfocou o estudo da contaminação provocada pelos principais metais pesados presentes em lixo urbano: $\mathrm{Cu}, \mathrm{Pb}, \mathrm{Zn}, \mathrm{Cd}, \mathrm{Ni}, \mathrm{Cr}, \mathrm{Ag}, \mathrm{Fe}$ e Mn. O elemento Li, embora não seja um metal pesado, foi também incluído no estudo sobre os solos, devido à sua presença nos materiais dispostos em aterros de lixo urbano. Os estudos buscaram, por um lado, mostrar o grau de po- luição das águas no local, identificando, também, a associação entre os metais, objeto principal desse estudo, e as características mineralógicas, químicas e físicas dos solos, como meio de avaliar o nível de contaminação da cobertura superficial na área do aterro. Por outro lado, objetivaram chamar a atenção dos responsáveis pela Superintendência de Limpeza Urbana da Prefeitura Municipal de Belo Horizonte sobre a situação ambiental no Aterro Sanitário da BR-040 e sobre os riscos de contaminação das águas subterrâneas da área e adjacências.

Devido a impossibilidade de publicar integralmente o trabalho e com o intuito de não prejudicar sua divulgação, achou-se por bem dividi-lo em três artigos seqüenciais, sendo este primeiro o que trata dos aspectos gerais da área, técnicas e métodos utilizados, enquanto que os próximos dois artigos a serem publicados, também pela REM, abordarão em detalhe e especificamente os estudos desenvolvidos sobre as águas, sedimentos de corrente e solos de todo $\mathrm{o}$ aterro sanitário.

\section{Localização da área}

A área estudada está localizada ao lado da BR-040, km 2, no sentido Belo Horizonte-Brasília, na Regional Noroeste do município de Belo Horizonte (Figura 1), limite com o município de Contagem.

\section{Contexto geológico e hidrogeológico}

O mapa geológico apresentado (Figura 2) mostra apenas parte da região do município de Belo Horizonte que se encontra mais intimamente ligada ao aterro sanitário, área de interesse do trabalho.

A geologia do município de Belo Horizonte é compreendida pelo chamado Domínio do Complexo Belo Horizonte, termo introduzido por Noce et al. (1994) e que representa $70 \%$ do território municipal, tendo sua área de maior expressão ao norte da calha do ribeirão Arrudas. Segundo Silva et al. (1995), nesse domínio predominam as rochas gnáissico-migmatíticas, bandadas, localmente milonitizadas.

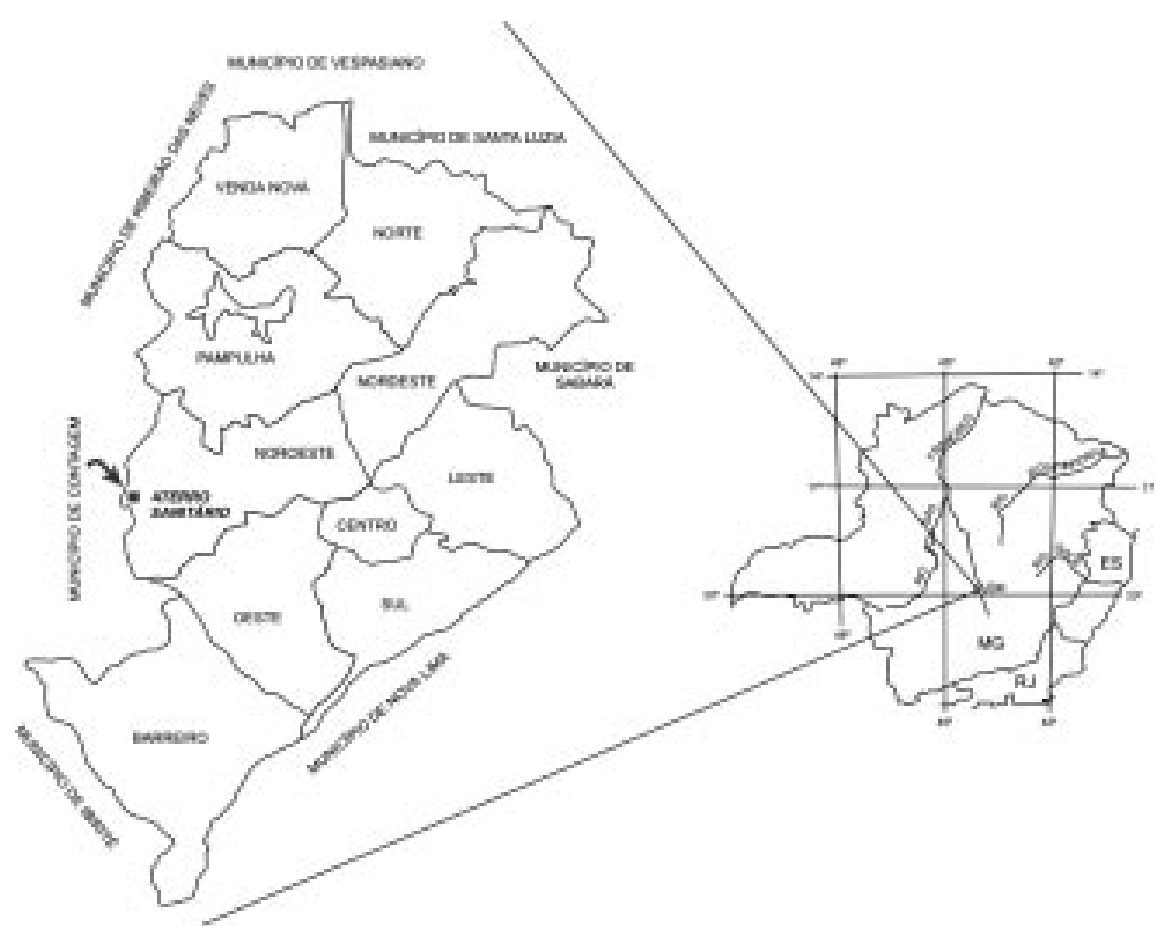

Figura 1 - Mapa do município de Belo Horizonte com a localização do Aterro Sanitário da Prefeitura Municipal de Belo Horizonte - MG. 
As Formações superficiais são representadas por solos residuais de espessura variada: o solo é raso ou ausente nas áreas de exposição dos maciços rochosos, espesso e silto-argiloso nas áreas de relevo muito suave. As maiores espessuras do manto de intemperismo encontram-se na Pampulha, atingindo valores de até $100 \mathrm{~m}$, conforme dados de perfuração de poços tubulares.

Sistemas de juntas e fraturas seccionam o Complexo Belo Horizonte segundo direções variadas, em geral com mergulhos fortes a verticais.

A geologia da área do aterro é compreendida, predominantemente, por diques de rochas básicas, ocupando aproximadamente $70 \%$ da área e por gnaisses migmatíticos do Complexo Belo Horizonte. Segundo a Figura 3.1, observa-se que o córrego dos Coqueiros corre sobre um fotolineamento, podendo, inclusive, redundar numa comunicação de suas águas com regiões mais profundas do maciço, caso seja um fraturamento penetrativo. As rochas encontram-se intemperizadas, apresentando uma cobertura superficial, cuja profundidade pode atingir até $20 \mathrm{~m}$ no domínio do gnaisse (dados de perfuração feita no local pela SLU).

O modelo hidrogeológico do município de Belo Horizonte (Silva et al., 1995) é composto por dois sistemas aqüíferos principais. $\mathrm{O}$ primeiro é o aqǘf́fero nas rochas do embasamento que constituem o chamado Complexo Belo Horizonte (domínio do embasamento cristalino), ocupando uma maior área. $\mathrm{O}$ segundo sistema é o encontrado nas rochas metassedimentares do Supergrupo Minas (domínios hidrogeológicos do Grupo Sabará e dos grupos Piracicaba e Itabira), que contêm as maiores reservas de água subterrânea, ocorrendo na porção sul do município.

Serão feitas considerações apenas sobre o sistema aqüífero do Complexo Belo Horizonte, sobre o qual encontrase o aterro sanitário da prefeitura municipal de Belo Horizonte. Esse sistema é do tipo livre, constituído, na sua parte superior, por rochas inconsistentes do manto de decomposição das rochas gnáissico-migmatíticas ou por material alúvio-coluvionar depositado sobre esse manto ou mesmo em rocha sã e, na parte inferior, por rochas fraturadas. Assim, têm-se um aquíffero granular poroso superior e um fissurado sotoposto, em comunicação hidráulica íntima, constituindo um só sistema.
Esse aqüífero apresenta, em geral, grande vulnerabilidade à poluição de suas águas, cuja recarga é realizada exclusivamente por infiltração de águas superficiais, em zonas de recarga preferencial, ou em todas as partes das subbacias, e, principalmente, por percolação de águas fluviais, a exemplo do Bairro Califórnia, que fica ao sul do aterro. A parte granular porosa superficial desse

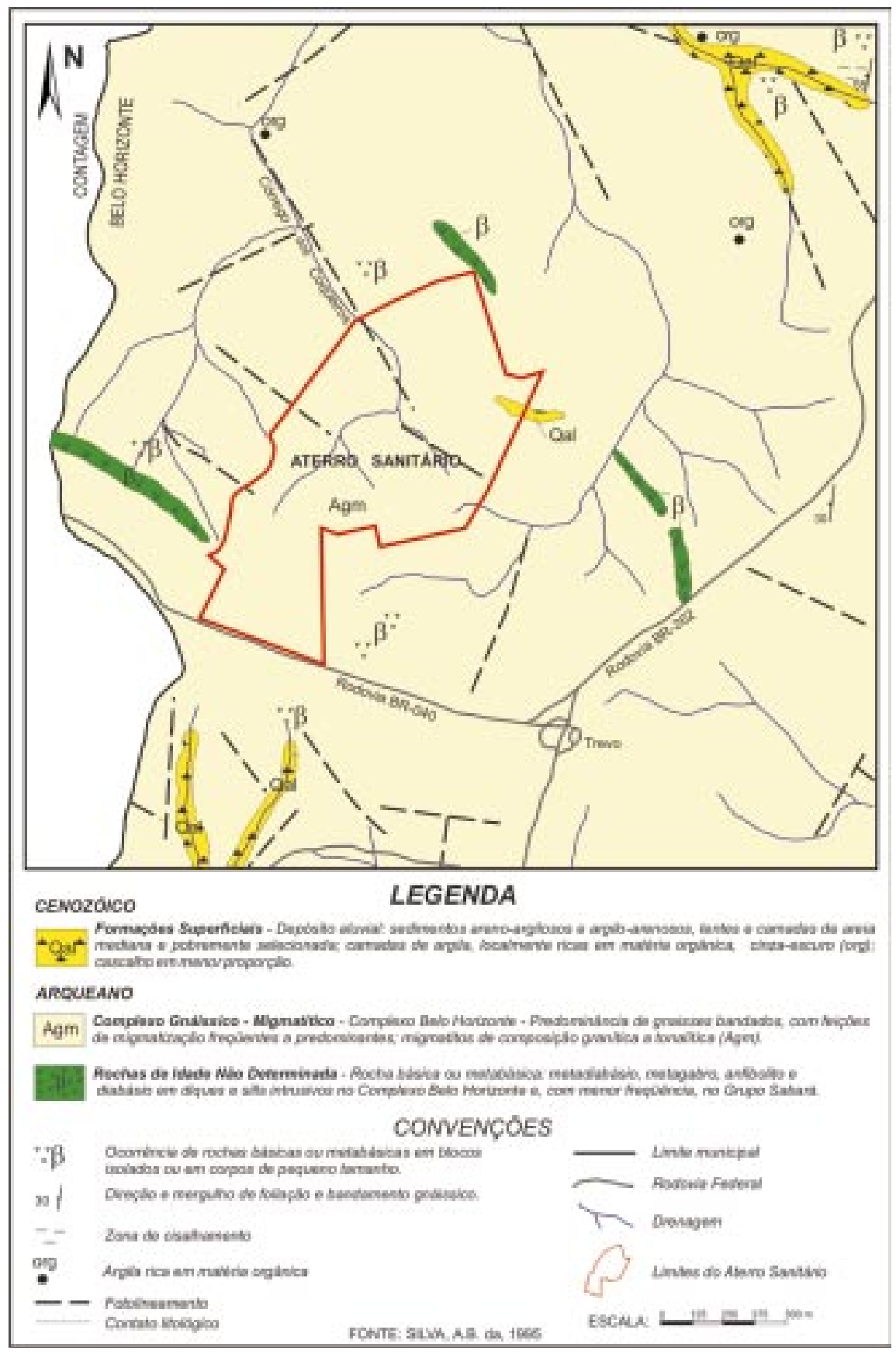

Figura 2 - Mapa geológico regional onde se encontra a área do Aterro Sanitário. 
aqüífero apresenta normalmente grande capacidade de infiltração de líquidos, o que o torna vulnerável à percolação de poluentes. Acresce-se, ainda, o fato de a cabeceira do córrego Ressaca, que deságua na lagoa da Pampulha, ter, como tributário, o córrego dos Coqueiros, que nasce dentro da área do aterro sanitário.

Por outro lado, as características hidrogeológicas do aterro sanitário propriamente dito, assentado sobre o aqüífero do Complexo Belo Horizonte, são pouco conhecidas ou estudadas em termos qualitativos. Os estudos existentes e feitos pela própria SLU, no ano de 1974, portanto, anteriores ao início do funcionamento do aterro, incluem $275,66 \mathrm{~m}$ de sondagem distribuídos em 23 poços ao longo de toda a área do aterro. Os dados mostram que o nível de água (N.A.) na área do aterro variava de $\pm 0,50 \mathrm{~m}$, nas baixadas, a $\pm 9,00 \mathrm{~m}$, nas partes medianamente elevadas. Em vários poços feitos nas partes elevadas não foi encontrado o nível de água.

\section{Características gerais do aterro sanitário}

O aterro, com área de 132ha (ver Figura 2), entrou em operação em 1973, contando, até 1997, com 4 bacias de disposição de lixo (Figura 3), panorama que começou a ser mudado com a implantação do projeto de biorremediação, ainda em andamento, caracterizado por acelerar a degradação do lixo pela inoculação de bactérias de alta resistência e com grande capacidade de transformação da celulose. Todo o lixo coletado no município de Belo Horizonte é atualmente disposto no Aterro Sanitário da BR-040.

Segundo dados fornecidos pela SLU, para o ano de 1994, havia uma po- pulação residente, acrescida da flutuante, de 2.500.000 habitantes. Desse total, aproximadamente $85 \%$ eram atendidos com serviços de limpeza urbana. A produção média de lixo/dia era de 3.204,41t, conforme indica a Quadro 1, considerando os 92 dias do $4^{\circ}$ trimestre de 1994. Atualmente a produção é superior a 4.300t/dia, segundo informação verbal da SLU.

\section{Material e métodos}

\subsection{Caracterização física e química do lixo}

As taxas de geração de lixo urbano no município de Belo Horizonte (SLUPrefeitura Municipal de Belo Horizonte, 1994) são as seguintes, tomando-se como base uma coleta em, aproximadamente, $70 \%$ da cidade:

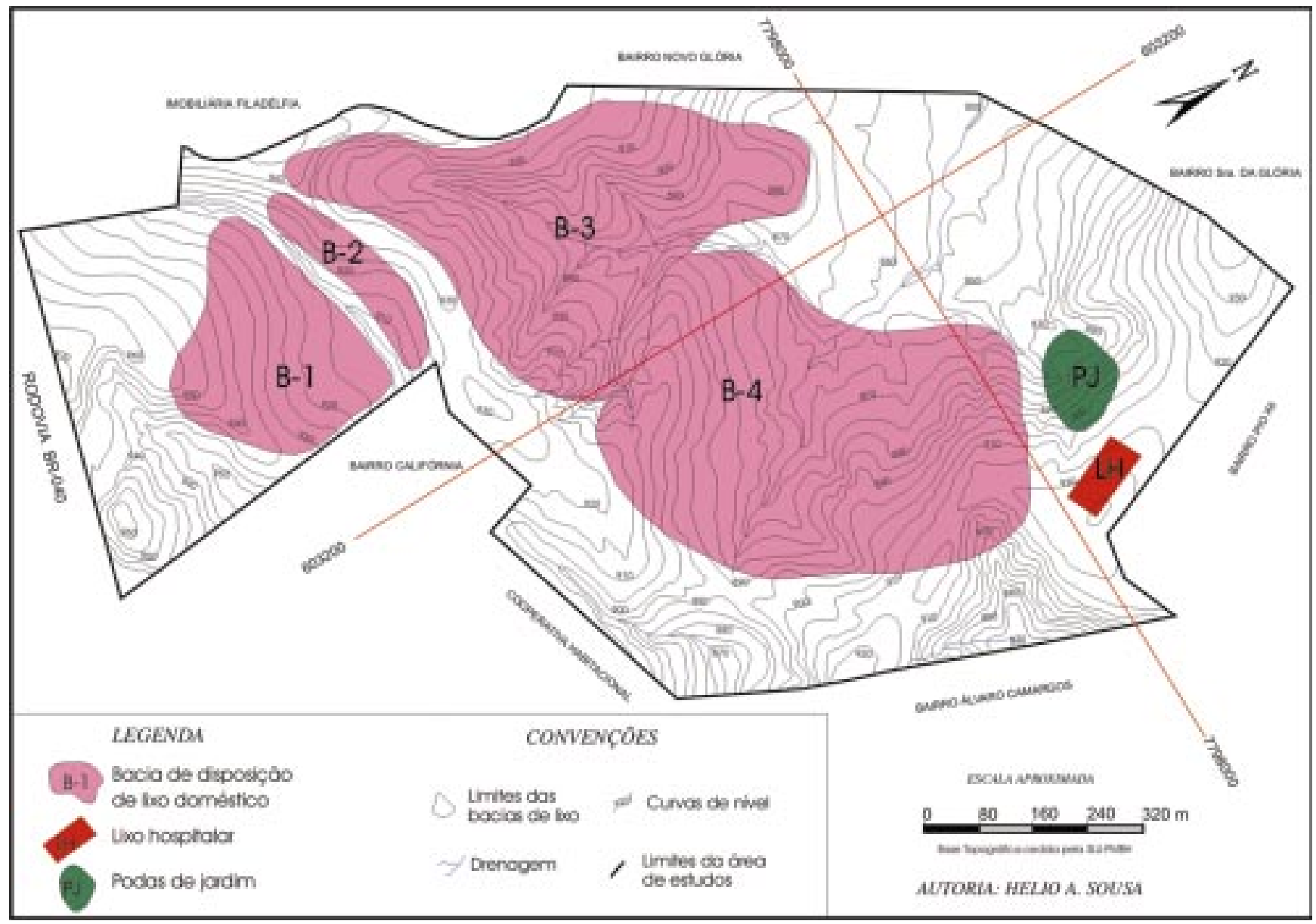

Figura 3 - Mapa de localização das bacias de lixo no período de 1997. 
Quadro 1 - Produção de lixo/dia na cidade de Belo Horizonte em 1994.

\begin{tabular}{l|r}
\hline \multicolumn{1}{c|}{ PROCEDÊNCIA DO LIXO } & \multicolumn{1}{|c}{ PRODUÇÃO MÉDIA (t) } \\
\hline Lixo domiciliar/comercial & 922,82 \\
\hline Lixo domiciliar recolhido por caçambas & 72,06 \\
\hline Lixo comercial usinado & 4,97 \\
\hline Lixo público & 952,49 \\
\hline Lixo unidades de saúde & 21,64 \\
\hline Entulho de construção civil & $1.200,00$ \\
\hline Resíduos de particulares & 30,43 \\
\hline TOTAL & $\mathbf{3 . 2 0 4 , 4 1}$ \\
\hline
\end{tabular}

Fonte: SLU/PMBH - Relatório trimestral de estatística (4ํTRIM/94).

\section{Classes de lixo}

-Lixo domiciliar/comercial

- Lixo público

- Lixo dos serviços de saúde

- Entulhos da construção civil

- Outros (grandes produtores)

A composição física do lixo antigo (Quadro 2) foi obtida de ensaios de segregação (SLU, 1994), tomando como base duas (2) amostras retiradas de locais diferentes, sem idades definidas. Essas amostras foram segregadas em três categorias:

- Segregado leve graúdo (SLG), que consiste de plásticos, trapos, couros, etc.

- Segregado pesado graúdo (SPG), que consiste de metais, vidros, pedras, etc.

- Segregado pesado miúdo (SPM), que consiste de matéria orgânica bioestabilizada e terra.

A composição química do lixo antigo (SLU, 1994) foi determinada em duas amostras, retiradas de locais diferentes no aterro, e os resultados são apresentados no Quadro 3.

A composição física dos resíduos urbanos gerados mais recentemente no município (SLU, 1994) evidencia que 64,4dag. $\mathrm{kg}^{-1}$ do lixo são compostos de resíduos orgânicos (matéria putrescível), 25dag. $\mathrm{kg}^{-1}$ de materiais potencialmente recicláveis (papel, plástico, vidro, metais) e 10,6dag. $\mathrm{kg}^{-1}$ de materiais descartáveis (trapos, couro, madeira, etc).

\subsection{Estudo das águas}

Para esse estudo foram coletadas nove (09) amostras, em uma única campanha de campo, sendo duas (02) de poços escavados (cisternas), uma (01) do córrego Coqueiros, a jusante do aterro, uma (01) da lagoa a jusante das bacias B-1 e B-2 de lixo, além de cinco (05) amostras de chorumes para análise da concentração de metais pesados no lixiviado (Figura 4).

Os métodos utilizados para as análises de águas de superfície foram baseados no "STANDARD Methods for the Examination of Water and Wastewater", $\left(19^{\text {th }}\right.$ Edition, 1995). Foram analisados, ao todo, 46 parâmetros para cada amostra. As amostras foram analisadas no laboratório de Análises de Água da CPRM Serviço Geológico do Brasil, Superintendência Regional de Belo Horizonte - MG.

\subsection{Estudos petrográficos de rochas}

Para caracterizar petrograficamente as rochas do aterro, foram realizados estudos petrográficos em apenas duas (02) amostras de rochas básicas, por inexistirem afloramentos de rochas gnáissicas, devido ao intenso intemperismo na área. As lâminas delgadas foram confec-

Quadro 2 - Resultado do ensaio de segregação do lixo antigo do Aterro Sanitário da BR-040 da Prefeitura Municipal de Belo Horizonte-MG.

\begin{tabular}{|c|c|c|c|c|c|}
\hline Categorias & Amostra $1(\mathrm{~kg})$ & Amostra $2(\mathrm{~kg})$ & Média (kg) & Valor (dag. $\left.\mathrm{kg}^{-1}\right)$ & $\begin{array}{c}\text { Valor ajustado } \\
\quad\left(\text { dag. } \mathrm{kg}^{-1}\right)\end{array}$ \\
\hline SLG & 12,7 & 2 & 7,4 & 27,7 & 27 \\
\hline SPG & 3,7 & 8,5 & 6,1 & 24 & 23 \\
\hline SPM & 11,5 & 14,6 & 13,1 & 49,2 & 50 \\
\hline Total & 27,9 & 25,1 & 26,5 & 100 & 100 \\
\hline
\end{tabular}

Fonte: LM - Tratamento de Resíduos (SLU, 1994). 
Quadro 3 - Resultados analíticos do lixo antigo do Aterro Sanitário da BR-040 da Prefeitura Municipal de Belo Horizonte-MG.

\begin{tabular}{|c|c|c|}
\hline AMOSTRAS & Amostra 1 & Amostra 2 \\
\hline PARÂMETROS & $\begin{array}{c}\text { (039, } \mathrm{n}^{\circ} \text { original) } \\
\left(\text { dag. } \mathrm{kg}^{-1}\right)\end{array}$ & $\begin{array}{c}\text { (040, no original) } \\
\left.\text { (dag. } \mathrm{kg}^{-1}\right)\end{array}$ \\
\hline Umidade original & 25,01 & 20,18 \\
\hline Umidade $\left(100-105^{\circ} \mathrm{C}\right)$ & 1,37 & 1,25 \\
\hline Potássio total $\left(\mathrm{K}_{2} \mathrm{O}\right)$ & 0,45 & 0,38 \\
\hline Sódio $(\mathrm{Na})$ & 0,13 & 0,10 \\
\hline Nitrogênio total $(\mathrm{N})$ & 0,35 & 0,31 \\
\hline Matéria orgânica & 13,43 & 9,54 \\
\hline Fósforo total $\left(\mathrm{P}_{2} \mathrm{O}_{5}\right)$ & 0,18 & 0,21 \\
\hline Fósforo solúvel em $\mathrm{H}_{2} \mathrm{O}\left(\mathrm{P}_{2} \mathrm{O}_{5}\right)$ & - & - \\
\hline Fósforo solúvel em ácido cítrico a 2\% relação 1/100 $\left(\mathrm{P}_{2} \mathrm{O}_{5}\right)$ & 0,15 & 0,15 \\
\hline Fósforo solúvel em citrato neutro de amônio $+\mathrm{H}_{2} \mathrm{O}$ & 0,14 & 0,19 \\
\hline Potássio solúvel em $\mathrm{H}_{2} \mathrm{O}\left(\mathrm{K}_{2} \mathrm{O}\right)$ & 0,17 & 0,14 \\
\hline Cálcio total $(\mathrm{CaO})$ & 2,60 & 3,70 \\
\hline Magnésio total (MgO) & 0,08 & 0,13 \\
\hline $\mathrm{R}_{2} \mathrm{O}_{3}\left(\mathrm{Fe}_{2} \mathrm{O}_{3}+\mathrm{Al}_{2} \mathrm{O}_{3}\right)$ & 16,20 & 15,00 \\
\hline $\mathrm{Fe}_{2} \mathrm{O}_{3}$ & 7,50 & 6,60 \\
\hline $\mathrm{Al}_{2} \mathrm{O}_{3}$ & 8,70 & 8,40 \\
\hline Insolúveis em $\mathrm{HCl}\left(\mathrm{SiO}_{2}\right)$ & 65,22 & 66,70 \\
\hline Cinza & 85,20 & 85,20 \\
\hline $\mathrm{pH}$ & 8,2 (s/ unid.) & 8,2 (s/ unid.) \\
\hline
\end{tabular}

Fonte: SLU-BH (1994).

cionadas no setor de Preparação de Amostras do DEGEO/UFOP, uma lâmina para cada ponto de coleta, cujas análises petrográficas foram feitas na Seção de Petrografia da CPRM/BH.

\subsection{Estudos geoquímicos de rochas e de sedimentos de corrente}

Foram coletadas duas (02) amostras de rochas básicas e apenas uma (01) amostra de sedimentos de corrente (Figura 4), com cerca de $1 \mathrm{~kg}$ cada uma e analisadas para $\mathrm{Cu}, \mathrm{Pb}, \mathrm{Zn}, \mathrm{Ni}, \mathrm{Cd}, \mathrm{Li}$, $\mathrm{Fe}, \mathrm{Mn}, \mathrm{Ag}$ e Cr. As amostras foram preparadas e analisadas em laboratórios da CPRM/BH, segundo métodos de preparação de amostras e de análises tendose como base o Manual Técnico de Análises Minerais do LAMIN-CPRM (1987) e em GEOANALYSIS (1992).

\subsection{Análises geoquímicas de rochas}

Inicialmente as amostras foram britadas em britador de mandíbula a uma granulometria de 10mesh, homogeneizadas e quarteadas. Numa segunda fase foram moídas em moinho de disco de porcelana até uma granulometria de 120 a 150mesh. Depois de peneiradas em (-) $150 \mathrm{mesh}$, as amostras foram homogeneizadas, de onde foram retiradas $\pm 25 \mathrm{~g}$ do material para análises.

Os elementos foram determinados por abertura total, sendo pesados $0,2 \mathrm{~g}$ de amostra a (-) 150mesh, aquecida em chapa, com $\mathrm{HNO}_{3}, \mathrm{HF}$ e $\mathrm{HClO}_{4}$, até a eliminação de fumaças brancas. $\mathrm{O}$ resíduo foi retomado com $\mathrm{HCl}$ 1:1 e levado à secura incipiente. O resíduo dessa etapa foi novamente retomado com $\mathrm{HCl} 10 \%$, sendo o material residual aquecido para solubilização. A solução foi transferida para uma proveta, sendo o volume completado com $\mathrm{HCl} 10 \%$. Os teores dos elementos foram determinados por Espectrometria de Absorção Atômica.

\subsection{Análises geoquímicas de sedimentos de corrente}

A amostra de sedimentos foi secada em estufa, a uma temperatura de 40 a $80^{\circ} \mathrm{C}$. Após esse procedimento, ela foi peneirada a 80 mesh (especificação ABNT no 80), depois quarteada, obtendo-se uma amostra de aproximadamente 100g. A amostra foi, então, pulverizada a 100mesh (especificação ABNT nº 100), transferindo-se o material fino para um frasco de polietileno devidamente identificado com número de lote, número de campo e número de laboratório. A amostra foi submetida a análises total e parcial. 


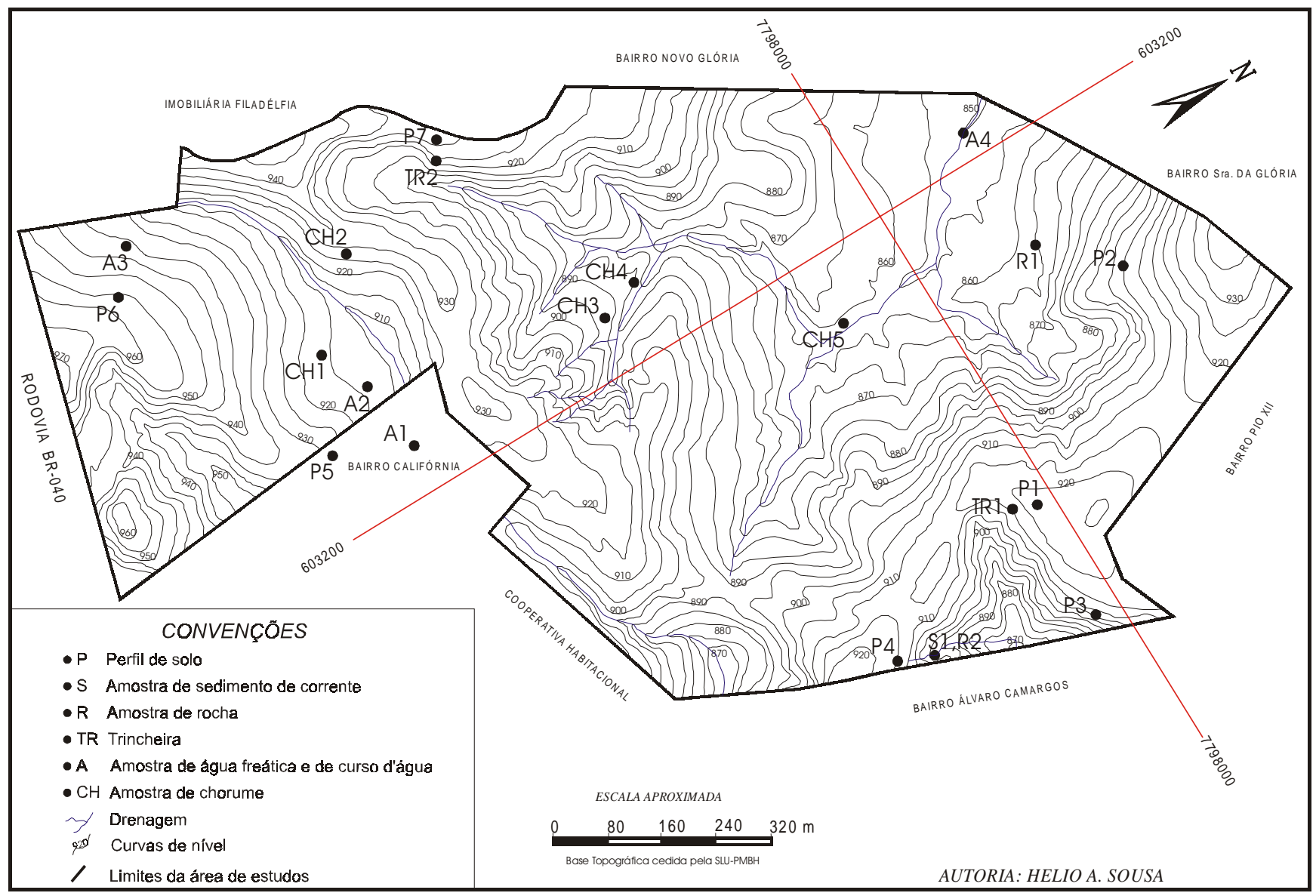

Figura 4 - Mapa de pontos de amostragem.

Para a análise total, a técnica foi a mesma adotada nas análises de rocha, anteriormente apresentada, com a diferença de que a granulometria utilizada para sedimentos é (-) 80mesh e não (-) 150mesh.

Para a determinação dos elementos por abertura parcial, foram pesados $0,2 \mathrm{~g}$ de amostra preparada a (-) 80mesh e titulada a frio com uma solução de EDTA $2,5 \%$, agitando por 15 minutos. Os teores dos elementos foram medidos por Espectrometria de Absorção Atômica.

$\mathrm{O} \mathrm{pH}$ da amostra foi determinado após agitação de $1 \mathrm{~g}$ de amostra com $100 \mathrm{~mL}$ de água destilada e período de repouso de 1 hora. Os valores de $\mathrm{pH}$ foram medidos usando-se um potenciômetro.

\subsection{Caracterização classificação dos solos}

Para caracterizar e classificar mais detalhadamente os solos, foi feito um mapeamento pedológico na escala 1:8.000, tendo-se como base os estudos de vários perfis, sendo determinadas seis (06) classes de solos. Eles foram classificados com base em avaliação de campo, em trincheiras e os dados foram respaldados por análises laboratoriais. As suas cores foram classificadas de acordo com a Carta de Cores de Munsell (1975) e a nomenclatura, baseada na cor, segundo Prado (1993).

Vale ressaltar que o solo do Perfil 1 não foi classificado como os demais, devido ao local de amostragem ter passado por processos de atividades antrópicas de decapeamento dos horizontes A e B originais. Atualmente, percebe-se o início da formação de novos horizontes, originados do material de entulho acumulado na área. Nesse estudo, a amostra coletada nos supostos horizontes, em formação, foi considerada como sendo de lixo posicionado sobre o horizonte $\mathrm{C}$.

\subsubsection{Amostragem}

Os materiais foram amostrados, após o mapeamento pedológico, em sete (07) perfis previamente selecionados, pela sua representatividade na área (Figura 4) e condições de amostragem. Foram escolhidas áreas sobrepostas por lixo e áreas não sobrepostas por lixo. Nas primeiras, foram coletadas ao todo 18 amostras dos horizontes A, B e C (Perfis 2 a 7). Nos perfis 2 e 5 , foram coletadas 6 amostras não-deformadas, uma em cada um dos seus horizontes A, B e C, para análises micromorfológicas. Em uma área sobreposta por lixo, foi amostrado o Perfil 1 , tendo em vista a facilidade de amostragem em um corte de estrada, escolhido propositadamente em um local de disposição de entulhos, com idade aproximada de 8 anos. Nesse perfil foram retiradas, ao todo, 06 amostras em espaçamentos de 0,50 em $0,50 \mathrm{~m}$, devido à indefinição de horizontes, sendo a primeira amostra coletada na base da pilha de entulhos já decompostos, próximo ao contato com o horizonte $\mathrm{C}$ do solo. 
Além disso, foram feitas duas (02) trincheiras com retroescavadeira, de aproximadamente 5,5-6 $\mathrm{m}$ de profundidade cada (Figura 4), sendo a primeira na bacia de lixo B-4, em local de solo derivado de rochas gnáissicas e lixo com idade aproximada de 3 a 4 anos e a segunda na bacia de lixo B-3, em local de solo derivado de rochas básicas e lixo com idade estimada em torno de 16 anos. Foram coletadas 2 amostras do solo abaixo da pilha de lixo na trincheira 1 (TR 1), sendo a primeira amostra no contato do lixo com o solo (primeiros $5 \mathrm{~cm}$ ) e a segunda $0,25 \mathrm{~m}$ abaixo; na trincheira 2 (TR 2) foram coletadas 4 amostras, sendo a primeira, também, no contato da pilha de lixo com o solo (primeiros $5 \mathrm{~cm}$ ) e as demais espaçadas $0,25 \mathrm{~m}$ umas das outras. No contato do lixo com o solo, na trincheira TR 2, foi coletada uma amostra não-deformada, para análises micromorfológicas.

A amostragem de perfis de solos sem lixo urbano sopreposto teve, como principal objetivo, caracterizar física e quimicamente os solos da área, além da obtenção de dados sobre as concentrações naturais de metais nas várias frações de retenção analisadas. As concentrações naturais dos metais, nos solos sem lixo sobreposto, servirão de parâmetro para as análises sobre as concentrações dos metais nos solos com lixo sobreposto, visando a identificar, por analogia, os horizontes cujas concentrações metálicas naturais sofreram modificações em função da presença do lixo no aterro. As amostras dos perfis de solo com lixo sobreposto contribuíram para os estudos sobre a concentração e distribuição dos metais nas áreas contaminadas.

As amostras coletadas, em quantidade suficiente ( $\pm 3 \mathrm{~kg}$ cada) para todas as análises químicas e físicas pertinentes, foram acondicionadas em sacos plásticos, etiquetadas e encaminhadas aos laboratórios.

\subsubsection{Caracterização química}

Os estudos de caracterização química dos solos foram feitos nos horizontes $\mathrm{A}, \mathrm{B}$ e $\mathrm{C}$ dos perfis 2 a 7, totalizando 18 amostras analisadas. Todas as análi- ses foram realizadas no Laboratório de Fertilidade do Solo da UFV.

As análises químicas incluíram a determinação do $\mathrm{pH}$ em $\mathrm{H}_{2} \mathrm{O}$, de $\mathrm{P}$, de $\mathrm{Al}$, cátions trocáveis $\left(\mathrm{Ca}^{2+}, \mathrm{Mg}^{2+} \mathrm{e} \mathrm{K}^{+}\right)$e acidez total $\left(\mathrm{H}^{+}+\mathrm{Al}^{3+}\right)$. Para a determinação de $\mathrm{P}$ e K, foi utilizado o extrator Mehlich 1, para $\mathrm{Al}, \mathrm{Ca}$ e $\mathrm{Mg}$, o extrator $\mathrm{KCl}$ a 1 mol. $L^{-1}$ e, para determinar $\mathrm{H}+\mathrm{Al}$, o extrator $\mathrm{Ca}(\mathrm{OAc}){ }_{2}$ a 0,5 mol. $\mathrm{L}^{-1}$, em pH 7,0. A capacidade de troca catiônica (CTC) foi determinada pelo método da soma de bases.

\subsubsection{Caracterização física}

A caracterização física dos solos foi feita no Laboratório de Fertilidade do Solo da UFV.

\subsubsection{Análises texturais}

A metodologia utilizada foi a mesma descrita pelo Método 1.16 da EMBRAPA (1979). As amostras de solo foram dispersas com $\mathrm{NaOH} 0,1$ mol.L $^{-1} \mathrm{e}$ agitação durante cerca de 15 minutos. A fração areia $(>230$ mesh ou $0,053 \mathrm{~mm})$ foi separada por tamização, a argila $(<2 \mu \mathrm{m})$, determinada pelo método da pipeta (sedimentação segundo a Lei de Stokes) e a fração silte, por diferença.

\subsubsection{Análises mineralógicas}

Dezoito (18) amostras de solo dos horizontes A, B e C dos Perfis 2 a 7 foram selecionadas para análises por DRX. As lâminas para estudos da fração argila foram preparadas no DEGEO/UFOP. As análises foram feitas no Laboratório de Química e Mineralogia do CDTN/CNEN (BH-MG).

As análises foram feitas utilizandose um difratômetro de Raios X de fabricação RIGAKU, modelo Geigerflex 3034, semi-automático, com goniômetro horizontal, monocromador de cristal curvo de grafite, tubo de cobre e porta-amostra giratório.

\section{Condições de operação}

Constante de tempo $=1 \mathrm{seg}$

Velocidade do goniômetro $=8^{\circ} 20 / \mathrm{min}$
Veloc. do registrador $=40 \mathrm{~mm} / \mathrm{min}$

Tensão $=40 \mathrm{Kv}$

Fator de escala $=8 \times 10^{2}$

Corrente $=30 \mathrm{~mA}$

A técnica utilizada para realização das análises mineralógicas obedeceram aos seguintes procedimentos:

- Preparação da amostra e obtenção da amostra analítica (150g).

- Separação granulométrica da amostra utilizando-se a série de peneiras tipo Tyler e obtenção das frações $-60+100$, $-100+325$ e -325 mesh .

- Deslamagem da fração -60 + 100mesh e separação densimétrica da fração deslamada, utilizando-se o bromofórmio como líquido separador (densidade $=2,84$ ) e obtenção das frações leves, intermediária e pesada.

- Separação magnética e eletromagnética da fração pesada utilizando-se, respectivamente, ímã de mão e separador eletromagnético Frantz e obtenção das frações ímã de mão, 0,25A, 0,25PM, $0,50 \mathrm{~A}$ e $0,50 \mathrm{PM}(\mathrm{A}=$ ampère e $\mathrm{PM}=$ paramagnética).

- Identificação dos constituintes minerais por difratometria de Raios X das frações obtidas e avaliação quantitativa de seus conteúdos.

Para os estudos da fração argila, foram utilizadas amostras de $5 \mathrm{~g}$ de solo e misturadas em um becker de $250 \mathrm{~mL}$ com um volume 4 vezes maior de água destilada e $0,5 \mathrm{~g}$ de pirofosfato de sódio $\left(\mathrm{Na}_{4} \mathrm{P}_{2} \mathrm{O}_{7}\right)$. A mistura foi agitada mecanicamente durante 6 minutos para homogeneizar o material, sendo posteriormente colocada em tubo de ensaio e levada ao ultra-som por cerca de 3 minutos para desagregar os minerais argilosos.

Os tubos de ensaio foram, então, levados à centrífuga durante 8 minutos a uma velocidade de 750 rpm, para separar a fração < $2 \mu \mathrm{m}$. A solução sobrenadante foi transferida para outros tubos de ensaio e centrifugada a uma velocidade de 5.000rpm durante 38 minutos. Depois de retirada a água límpida sobrenadante, usou-se o material precipitado para confeccionar as lâminas orientadas. 


\subsubsection{Análises micromorfológicas}

Com a meta de identificar, principalmente, as feições pedogenéticas, ligadas a processos de eluviação/iluviação, devido à percolação de água, foram estudadas e descritas 8 lâminas delgadas de amostras não deformadas, sendo seis (06) referentes aos solos não sobrepostos por lixo urbano (horizontes A, B e C dos perfis $\mathrm{P} 2$ e $\mathrm{P} 5$, respectivamente, sobre rochas básicas e gnáissicas) e as duas (02) restantes da zona de transição entre a pilha de lixo e o solo da trincheira TR 2 sobre rochas básicas (bacia de lixo B-3).

As amostras foram secadas em estufa, a $80^{\circ} \mathrm{C}$, durante 1 hora, e depois impregnadas com araldite a uma proporção de 10 x 1 (endurecedor), adicionando-se 3 partes de álcool absoluto. Novamente foram colocadas na estufa por \pm 15 minutos até a secagem total. Após o processo de secagem total, a amostra foi serrada para a confecção das lâminas delgadas. As amostras e as lâminas foram preparadas e descritas no DEGEO/ UFOP.

Para a descrição das lâminas delgadas utilizaram-se o microscópio ótico ZEISS e as fotomicrografias tiradas com teleobjetiva de aumento 10x. A nomenclatura utilizada no estudo teve como base Brewer (1964) e Lima et al. (1985).

\subsubsection{Análises geoquímicas}

As amostras de solo foram preparadas e analisadas no LAMIN (SGB-CPRM/RIO), sendo submetidas a um procedimento analítico-seqüencial (Fletcher, 1981) das frações trocável, matéria orgânica, óxidos de Fe-Mn e fração total, para melhor compreender o comportamento dos elementos químicos e suas interações físico-químicas com o solo.

\subsubsection{Fração trocável}

Para a determinação da concentração de metais associados à fração trocável, foi utilizado $1 \mathrm{~g}$ de amostra preparada a (-) 80mesh (preparação padrão de solos) com solução $1 \mathrm{~mol} . \mathrm{L}^{-1}$ de acetato de sódio e a amostra foi agitada por 30 minutos e depois centrifugada, transferindo-se a solução sobrenadante para uma proveta, sendo o volume completado para $20 \mathrm{~mL}$ com acetato de sódio. Os teores dos elementos foram medidos por Espectrometria de Absorção Atômica (AA).

\subsubsection{Fração matéria orgânica}

O resíduo insolúvel da operação anterior foi agitado com solução de hipoclorito de sódio e aquecido em banhomaria por 3 horas. Depois de centrifugada, a solução sobrenadante foi transferida para uma proveta, sendo o volume completado para $20 \mathrm{~mL}$ com hipoclorito de sódio. Os teores dos elementos extraídos dos sítios de adsorção foram medidos por Espectrometria de Absorção Atômica.

\subsubsection{Fração óxidos hidratados de manganês}

A concentração de metais pesados nos óxidos hidratados de manganês foi determinada utilizando-se o resíduo insolúvel da operação anterior, que foi agitado com solução $0,1 \mathrm{~mol} . \mathrm{L}^{-1}$ de cloridrato de hidroxilamina em $\mathrm{HNO}_{3} 0,01 \mathrm{~mol} . \mathrm{L}^{-1}$ por 30 minutos. Depois de centrifugada, a solução sobrenadante teve seu volume completado para $20 \mathrm{~mL}$ com a solução extratora. Os teores dos elementos foram medidos por Espectrometria de Absorção Atômica.

\subsubsection{Fração óxidos hidratados de ferro}

Para a determinação dos metais adsorvidos nos óxidos hidratados de ferro, o resíduo insolúvel da operação anterior foi agitado com solução $0,1 \mathrm{~mol} \cdot \mathrm{L}^{-1}$ de cloridrato de hidroxilamina em $\mathrm{HCl}$ 0,25 mol. $\mathrm{L}^{-1} \mathrm{e}$ aquecido em banho-maria, a $70^{\circ} \mathrm{C}$. Após o aquecimento, a solução foi agitada por 5 minutos e centrifugada, sendo o material sobrenadante transferido para uma proveta, completando-se o volume para $20 \mathrm{~mL}$ com solução 0,1 mol. $\mathrm{L}^{-1}$ de hidroxilamina em $\mathrm{HNO}_{3}$ $0,01 \mathrm{~mol} \cdot \mathrm{L}^{-1}$. Os teores dos elementos foram medidos por Espectrometria de Absorção Atômica.

\subsubsection{Fração total}

Para abertura total das amostras, foram pesados $0,2 \mathrm{~g}$ de amostra preparada a (-) 80mesh, aquecida em chapa, com $\mathrm{HNO}_{3}, \mathrm{HF}$ e $\mathrm{HClO}_{4}$ até a eliminação de fumaças brancas. O resíduo foi retomado com $\mathrm{HCl}$ 1:1 e levado à secura incipiente. $\mathrm{O}$ resíduo de fundo foi novamente retomado com $\mathrm{HCl} 100 \%$ e aquecido para solubilização. A solução foi, então, transferida para uma proveta, onde teve seu volume completado para $20 \mathrm{~mL}$ com $\mathrm{HCl} 100 \%$. Os teores dos elementos foram medidos por Espectrometria de Absorção Atômica.

\subsection{Interpretação dos dados geoquímicos}

A caracterização da área estudada foi obtida com base nos dados físicos e químicos dos solos e da geologia local. $\mathrm{O} \mathrm{Cd}$ e a $\mathrm{Ag}$ foram excluídos das considerações em razão de não terem sido detectados pelos métodos adotados.

Os resultados foram organizados e separados em apenas dois grupos de dados, tornando a interpretação mais objetiva e prática, a saber: grupo de solos não sobrepostos por lixo urbano (Perfis 2 a 7) e grupo de solos sobrepostos por entulhos de construção (Perfil 1) e por lixo urbano (Trincheira TR1 da bacia de lixo B-4 e Trincheira TR2 da bacia de lixo B-3).

\section{Conclusões}

O levantamento realizado constituise num método de aplicação prática para estudos ambientais em áreas de aterro sanitário, ou mesmo em áreas de lixão, que visem, sobretudo, à avaliação do grau de poluição das águas (subterrâneas e superficiais) e dos solos submetidos a impactos provocados pela disposição de rejeitos sólidos urbanos.

\section{Agradecimentos}

O autor agradece aos Professores Dr. Hubert M. Roeser (DEGEO/ UFOP), Dr. Antônio Teixeira de Matos (Depart. Eng. Agrícola/UFV), Dr. Liovando Mar- 
ciano da Costa (Depart. Solos/ UFV), Dra. Angélica D. Varajão (DEGEO/ UFOP); aos órgãos CPRM/SUREG-BH, SLU/PMBH, CDTN/CNEN-BH; ao Dr. Cláudio Raposo (CDTN-CNEN-BH) e a todos os demais que, direta ou indiretamente, contribuíram para a consecução dos trabalhos.

\section{Referências}

\section{Bibliográficas}

ASSOCIAÇÃO BRASILEIRA DE NORMAS TÉCNICAS (ABNT). Solo e sedimentos de corrente - Peneiramento e pulverização de material em malhas. NBR 80, 100, 140. 1987.

BREWER, R. Fabric and mineral analysis of soils. New York: John Wiley \& Sons, 1964. $482 \mathrm{p}$.
EMBRAPA - Manual de Métodos de Análise de Solos - Serviço Nacional de Levantamento e Conservação de Solos (SNLCS), 1979 snp (sem nota de paginação).

FLETCHER, W.K. Analytical methods in geochemical prospecting. Elsevier Scientific Publishing Company, Amsterdam, 1981. v. 1, 92p.

GEOANALYSIS. Journal of Geochemical Exploration, 44, p.1-3. 1992.

LAMIN-CPRM. Manual Técnico de Análises Minerais, versão 1.0, out. de 1987 snp (sem nota de paginação).

LIMA, P.C., CURI, N., LEPSCH, I.F. Terminologia de micromorfologia do solo. Campinas: Boletim Informativo da SBCS, 1985. v. 10 , p. 33-34.

MUNSELL COLOR - Munsell Soil Color Charts, Macbeth Division of Kollmorgen Corporation. Baltimore, Maryland. 1975.
NOCE, C.M., MACHADO, N., TEIXEIRA, W. O complexo Belo Horizonte e a evolução arqueana do Quadrilátero Ferrífero, Minas Gerais. In: CONGRESSO BRASILEIRO DE GEOLOGIA, 38, 1994. Camboriú. Boletim de resumos expandidos... Porto Alegre: SBG/DNPM/ CPRM, 1994. v.1, p.68-69.

PRADO, H. Manual de Classificação de Solos do Brasil. Jaboti Cabral, FUNEP, 1993.218p.

SILVA, A.B., CARVALHO, E.T., FANTINELI, L.M., ROMANO, A.W., VIANA, C.S. Estudos geológicos, hidrogeológicos, geotécnicos e geoambientais integrados no Município de Belo Horizonte. Relatório Final. Belo Horizonte. Prefeitura Municipal de Belo Horizonte. UFMG/IGC/ FUNDEP, 1995. 150p.

STANDARD Methods for the Examination of Water and Wastewater. Edited by Andrew D. Eaton, Lenore S. Clesceri and Arnold E. Greenberg. 19th Edition. 1995.

\section{Descubra as muitas informações da:}

Geologia, Mineração,
Metalurgia \& Materiais e Engenharia Civil.

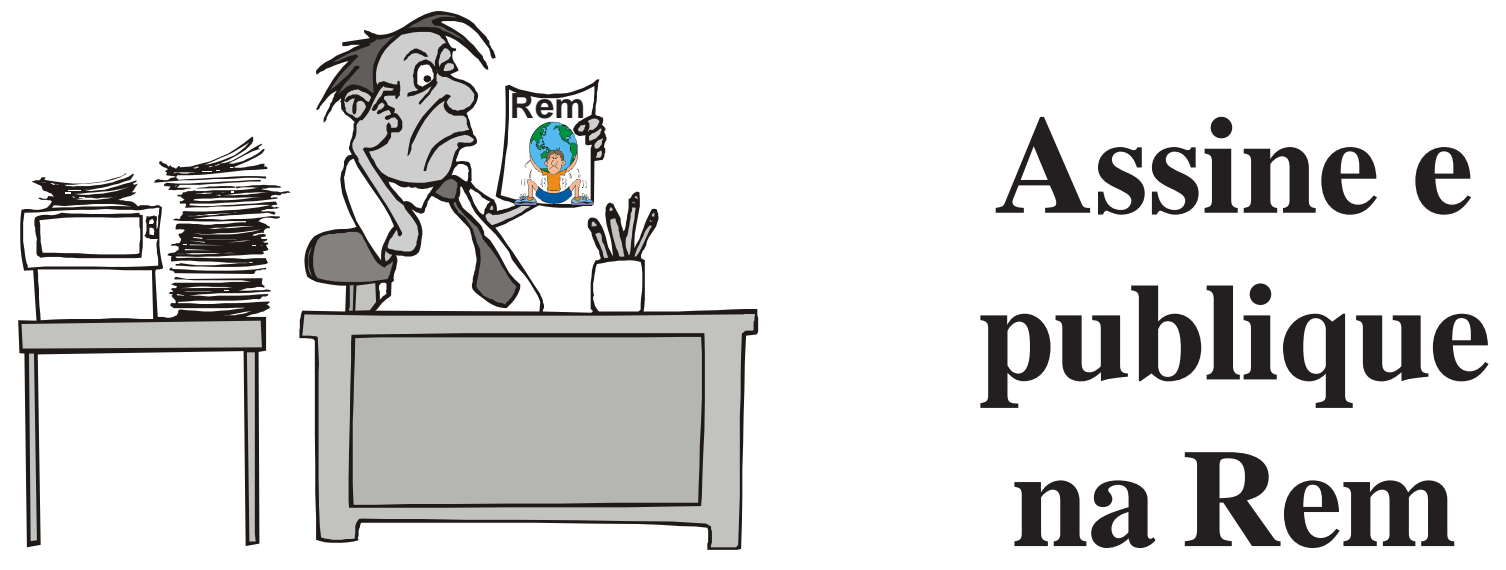

Fone/Fax: (31) 3551- 4730 - E-mail: remjorio@ouropreto.feop.com.br 